\title{
Auralization of NASA N+2 Aircraft Concepts from System Noise Predictions
}

\author{
Stephen A. Rizzi ${ }^{1}$, Casey L. Burley ${ }^{2}$, and Russell H. Thomas ${ }^{3}$ \\ NASA Langley Research Center, Hampton, VA 23681, USA
}

\begin{abstract}
Auralization of aircraft flyover noise provides an auditory experience that complements integrated metrics obtained from system noise predictions. Recent efforts have focused on auralization methods development, specifically the process by which source noise information obtained from semi-empirical models, computational aeroacoustic analyses, and wind tunnel and flight test data, are used for simulated flyover noise at a receiver on the ground. The primary focus of this work, however, is to develop full vehicle auralizations in order to explore the distinguishing features of NASA's N+2 aircraft vis-à-vis current fleet reference vehicles for single-aisle and large twin-aisle classes. Some features can be seen in metric time histories associated with aircraft noise certification, e.g., tone-corrected perceived noise level used in the calculation of effective perceived noise level. Other features can be observed in sound quality metrics, e.g., loudness, sharpness, roughness, fluctuation strength and tone-to-noise ratio. A psychoacoustic annoyance model is employed to establish the relationship between sound quality metrics and noise certification metrics. Finally, the auralizations will serve as the basis for a separate psychoacoustic study aimed at assessing how well aircraft noise certification metrics predict human annoyance for these advanced vehicle concepts.
\end{abstract}

\section{Nomenclature}

$\begin{array}{ll}c & =\text { speed of sound } \\ D_{\text {Full-Scale }} & =\text { full-scale fan diameter } \\ D_{\text {Model-Scale }} & =\text { model-scale fan diameter } \\ f & =\text { frequency }(\mathrm{Hz}) \\ M & =\text { Mach number } \\ P & =\text { static pressure } \\ S F & =\text { geometric scale factor }\left(D_{\text {Model-Scale }} / D_{\text {Full-Scale }}\right) \\ \rho & =\text { air density } \\ \theta_{E} & =\text { noise emission (polar) angle } \\ \theta_{G} & =\text { geometric sideline microphone array angle }\end{array}$

\section{Introduction}

SINCE its inception in 2009, the NASA Environmentally Responsible Aviation (ERA) project has focused on

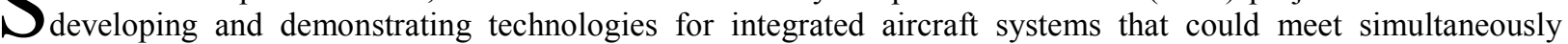
aggressive goals for fuel burn, noise, and emissions. ${ }^{1}$ The fuel burn goal is for a reduction of $50 \%$ relative to a bestin-class aircraft in 2005; the noise goal is 42 EPNdB cumulative below the Stage 4 requirement; ${ }^{2,3}$ and the emissions goal is for a reduction of $75 \%$ in NOx below the International Civil Aviation Organization (ICAO) Committee on Aviation Environmental Protection (CAEP) 6 standard. The target date is 2020 for key technologies to be at a technology readiness level (TRL) of 4-6 (system or sub-system prototype demonstrated in a relevant environment). This timeline corresponds to a projected aircraft entry into service of 2025. These goals with the timeframe are defined by NASA with the term $\mathrm{N}+2$.

The approach taken to achieve these goals has focused on development of advanced multidiscipline-based concepts and technologies, and highly integrated engine/airframe configurations. A recent noise assessment

\footnotetext{
${ }^{1}$ Senior Researcher for Aeroacoustics, Aeroacoustics Branch, MS 463, Associate Fellow AIAA

${ }^{2}$ Senior Research Engineer, Aeroacoustics Branch, MS 463, Senior Member AIAA

${ }^{3}$ Senior Research Engineer, Aeroacoustics Branch, MS 463, Senior Member AIAA
} 
demonstrated that the noise goal is achievable for certain configurations using a combination of ERA technologies in the "N+2" vehicle plus additional Integrated Technology Demonstration (ITD) noise reduction technologies. ${ }^{4}$ In many cases, the resulting configurations and advanced aircraft technologies substantially differ from the familiar tube and wing designs constituting the current fleet. Therefore, the following question arises: How well do aircraft certification metrics, based on psychoacoustic studies conducted in the 1960s and ' $70 \mathrm{~s}$ using measured noise from tube and wing designs with low bypass ratio turbofan engines, reflect the human annoyance of these advanced vehicle concepts? As the new concepts are yet to be built, it is not possible to test human response using measured flyover noise. Fortunately, auralization has been shown to be an effective means of simulating aircraft flyover noise using semi-empirical models, ${ }^{5}$ computational aeroacoustic analyses, ${ }^{6}$ and wind tunnel ${ }^{7}$ and flight $^{8}$ test data to characterize the source. The auralization process itself involves: source noise synthesis, using one or more of the above, in a frame with the moving source; and propagation of the resulting pressure time history through application of a time-varying: gain to simulate spherical spreading; time delay to Doppler shift; and filter to simulate atmospheric absorption and ground plane impedance. Auralization of selected $\mathrm{N}+2$ aircraft concepts are subsequently performed in a manner consistent with the system noise assessments, resulting in comparable integrated noise metrics. Sound quality metrics, e.g., loudness, sharpness, roughness, fluctuation strength and toneto-noise ratio, are then explored to give insight into psychoacoustic differences between concepts. A psychoacoustic annoyance model is employed to establish the relationship between sound quality metrics and noise certification metrics. The resulting auralizations form the basis of a separate human response study aimed at assessing how well aircraft noise certification metrics predict human annoyance for these advanced vehicle concepts. ${ }^{9}$

\section{N+2 Aircraft Concepts}

Auralizations were performed for seven concepts selected from a greater number considered under the ERA final noise assessments. ${ }^{4}$ These are the five $\mathrm{N}+2$ concepts

- a single-aisle (SA), 160 passenger class tube and wing aircraft (T+W160) with two small geared turbofan (GTF) engines,

- a large twin-aisle (LTA), 301 passenger class tube and wing aircraft (T+W301) with two large direct drive (DD) engines,

- an LTA T+W301 aircraft with two large GTF engines,

- an LTA hybrid wing body aircraft (HWB301) with two large GTF engines,

- an LTA mid-fuselage nacelle aircraft (MFN301) with two large GTF engines,

and two reference vehicles

- a Boeing 737-800-like aircraft with two CFM56-like direct drive engines (reference vehicle for the $\mathrm{T}+\mathrm{W} 160$ vehicle in the SA class), and

- a Boeing 777-200LR-like aircraft with two GE90-110B-like direct drive engines (reference vehicle for the T+W301, HWB301 and MFN301 in the LTA class).

The $\mathrm{N}+2$ configurations are depicted in Figure 1. For each of the $\mathrm{N}+2$ configurations, two technology levels were considered: "N+2" and "N+2 + Integrated Technology Demonstration (ITD) Noise Reduction." The "N+2" configurations include ERA technologies inherent in the airframe and engine design as well as noise reduction technologies. ${ }^{4}$ The "N+2 + ITD" configurations additionally included stator soft vane liner treatment for fan noise, partial main landing gear fairing, and flap-side edge treatment for tube and wing aircraft with high lift flaps. ${ }^{4}$ Auralizations were performed at approach and sideline (takeoff) certification conditions. The above constitutes a total of twenty-four conditions, see Table 1 . The shorthand name will subsequently be used to indicate the aircraft type, engine type, and technology level. 
$\mathrm{T}+\mathrm{W} 160$

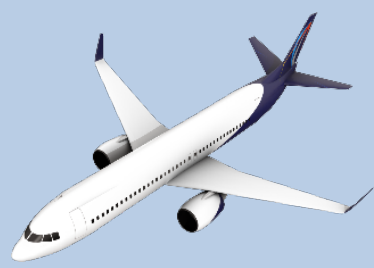

HWB301

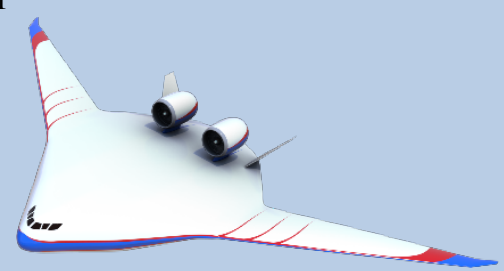

$\mathrm{T}+\mathrm{W} 301$

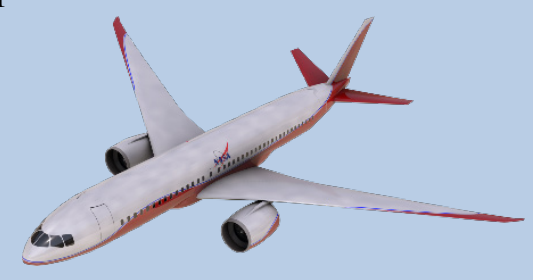

MFN301

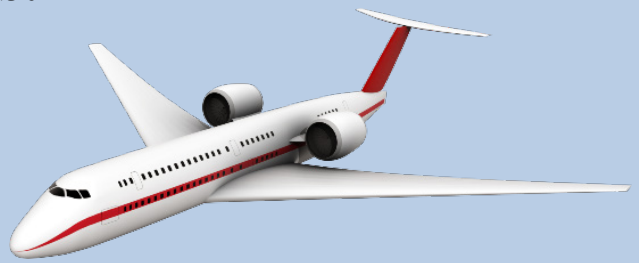

Figure 1: $\mathrm{N}+2$ aircraft configurations under investigation.

Table 1: Summary of aircraft auralizations.

\begin{tabular}{|c|c|c|c|c|c|}
\hline ID & Aircraft & Engine & Condition & Technology Level & Shorthand Name \\
\hline 1 & \multirow{2}{*}{ 777-GE90-110B-like } & \multirow{2}{*}{ DD } & Approach & \multirow{2}{*}{ Reference } & \multirow{2}{*}{ LTA-Ref } \\
\hline 2 & & & Sideline & & \\
\hline 3 & \multirow{2}{*}{ 737-CFM56-like } & \multirow{2}{*}{$\mathrm{DD}$} & Approach & \multirow{2}{*}{ Reference } & \multirow{2}{*}{ SA-Ref } \\
\hline 4 & & & Sideline & & \\
\hline 5 & \multirow{4}{*}{$\mathrm{T}+\mathrm{W} 301$} & \multirow{4}{*}{ GTF } & \multirow{2}{*}{ Approach } & $\mathrm{N}+2$ & $\mathrm{~T}+\mathrm{W} 301-\mathrm{GTF}$ \\
\hline 6 & & & & $\mathrm{~N}+2+$ ITD & T+W301-GTF-ITD \\
\hline 7 & & & \multirow{2}{*}{ Sideline } & $\mathrm{N}+2$ & $\mathrm{~T}+\mathrm{W} 301-\mathrm{GTF}$ \\
\hline 8 & & & & $\mathrm{~N}+2+$ ITD & T+W301-GTF-ITD \\
\hline 9 & \multirow{4}{*}{$\mathrm{T}+\mathrm{W} 301$} & \multirow{4}{*}{ DD } & \multirow{2}{*}{ Approach } & $\mathrm{N}+2$ & $\mathrm{~T}+\mathrm{W} 301-\mathrm{DD}$ \\
\hline 10 & & & & $\mathrm{~N}+2+$ ITD & T+W301-DD-ITD \\
\hline 11 & & & \multirow{2}{*}{ Sideline } & $\mathrm{N}+2$ & T+W301-DD \\
\hline 12 & & & & $\mathrm{~N}+2+$ ITD & T+W301-DD-ITD \\
\hline 13 & \multirow{4}{*}{ MFN301 } & \multirow{4}{*}{ GTF } & \multirow{2}{*}{ Approach } & $\mathrm{N}+2$ & MFN301-GTF \\
\hline 14 & & & & $\mathrm{~N}+2+$ ITD & MFN301-GTF-ITD \\
\hline 15 & & & \multirow{2}{*}{ Sideline } & $\mathrm{N}+2$ & MFN301-GTF \\
\hline 16 & & & & $\mathrm{~N}+2+$ ITD & MFN301-GTF-ITD \\
\hline 17 & \multirow{4}{*}{$\mathrm{T}+\mathrm{W} 160$} & \multirow{4}{*}{ GTF } & \multirow{2}{*}{ Approach } & $\mathrm{N}+2$ & $\mathrm{~T}+\mathrm{W} 160-\mathrm{GTF}$ \\
\hline 18 & & & & $\mathrm{~N}+2+$ ITD & $\mathrm{T}+\mathrm{W} 160-\mathrm{GTF}-\mathrm{ITD}$ \\
\hline 19 & & & \multirow{2}{*}{ Sideline } & $\mathrm{N}+2$ & $\mathrm{~T}+\mathrm{W} 160-\mathrm{GTF}$ \\
\hline 20 & & & & $\mathrm{~N}+2+$ ITD & $\mathrm{T}+\mathrm{W} 160-\mathrm{GTF}-\mathrm{ITD}$ \\
\hline 21 & \multirow{4}{*}{ HWB301 } & \multirow{4}{*}{ GTF } & \multirow{2}{*}{ Approach } & $\mathrm{N}+2$ & HWB301-GTF \\
\hline 22 & & & & $\mathrm{~N}+2+\mathrm{ITD}$ & HWB301-GTF-ITD \\
\hline 23 & & & \multirow{2}{*}{ Sideline } & $\mathrm{N}+2$ & HWB301-GTF \\
\hline 24 & & & & $\mathrm{~N}+2+$ ITD & HWB301-GTF-ITD \\
\hline
\end{tabular}




\section{System Noise Assessments}

The ERA final noise assessments ${ }^{4}$ were performed using the framework of the NASA Aircraft Noise Prediction Program 2 (ANOPP2) ${ }^{10}$ Each predicted component to be auralized consisted of a combination of a predicted source and the impacts of additional technologies and propulsion airframe aeroacoustic interactions. A summary of source noise prediction and source noise synthesis methods used is provided in Table 2. All prediction methods used are semi-empirical methods within the ANOPP ${ }^{11}$ module of ANOPP2, with the exception of GTF broadband fan noise, GTF fan tones, soft vane treatment, partial landing gear fairing, and propulsion airframe aeroacoustic interactions. The multiple degree-of-freedom duct acoustic liner treatment was computed using a modified version of the ANOPP TREAT module. The application of any given noise source prediction method, including its treatments and suppressions, is configuration dependent and is not indicated in Table 2, but can be found in Thomas et al. ${ }^{4}$

Table 2: Summary of source noise prediction and auralization methods used.

\begin{tabular}{|l|l|l|l|}
\hline \hline \multicolumn{2}{|l|}{ Noise component } & Prediction Method & Synthesis Method \\
\hline \hline \multirow{2}{*}{ DD broadband fan } & Forward & ANOPP-HDNFAN & Broadband \\
\cline { 2 - 4 } & Aft & ANOPP-HDNFAN $^{12}$ & Broadband \\
\hline \multirow{2}{*}{$\begin{array}{l}\text { DD R-S interaction } \\
\text { tones }\end{array}$} & Forward & ANOPP-HDNFAN $^{12}$ & Tonal \\
\cline { 2 - 4 } & Aft & ANOPP-HDNFAN $^{12}$ & Tonal \\
\hline GTF broadband fan & ANOPP-ACD $^{11}$ & Broadband \\
\hline GTF fan tones & ANOPP-ACD $^{11}$ & Tonal \\
\hline Core noise & ANOPP-GECOR $^{13}$ & Broadband \\
\hline Jet noise & ANOPP-ST2JET $^{14}$ & Broadband \\
\hline Nose landing gear & ANOPP-BAF $^{15}$ & Broadband \\
\hline Main landing gear & ANOPP-BAF $^{15}$ & Broadband \\
\hline Flap & ANOPP-BAF $^{16}$ & Broadband \\
\hline Slats & ANOPP-BAF $^{17}$ & Broadband \\
\hline Trailing edge & ANOPP-FNKAFM & Broadband \\
\hline
\end{tabular}

Additional focus on the GTF fan noise prediction follows, as it has a direct bearing on the auralization process. The prediction is based on model-scale acoustic measurements made in the 9x15 wind tunnel at the NASA John H. Glenn Research Center at Lewis Field, instead of a semi-empirical model. The prediction of the integrated GTF fan noise incorporates the predicted impacts of several design features with the measured data in order to properly represent the $\mathrm{N}+2$ GTF fan configuration at the proper operating conditions specific to the flight path of the $\mathrm{N}+2$ vehicle. The data processing steps required for scaling and flight effects largely follow the methods previously developed for system noise prediction of HWB aircraft ${ }^{20,21}$ and auralization of open rotor engines. ${ }^{7}$ That method was itself adopted from the process developed by Guynn et al. ${ }^{22}$ for converting scale model wind tunnel acoustic data to full scale flight condition data. The process is summarized below.

\section{A. Pre-Processing}

Calibrated microphone-corrected narrowband wind tunnel sound pressure level (SPL) data (dB) were adjusted to a $1 \mathrm{ft}$. free-field, lossless condition through application of an inverse atmospheric attenuation model and spherical spreading loss correction. In the aforementioned open rotor study, coherent tonal noise was separated from incoherent broadband noise for synthesis considerations alone. There, the systems analysis used a single total noise component. In the present work, the need to apply treatments and suppressions specific to each component requires that they be separated for both the systems analysis and for the auralization. While this step could be deferred to the end of the tunnel-to-flight condition processing, it was applied at the start.

The separation process follows that used in the open rotor study, but is adapted to model-scale. A 10-point median filter was applied to the $1 \mathrm{ft}$. free-field, lossless spectra and spectral lines exceeding the median value were replaced by the median value to obtain the broadband component spectra. ${ }^{23}$ This component was subtracted from the original $1 \mathrm{ft}$. free-field, lossless spectra to obtain the tonal component spectra. The tonal amplitudes at the model-scale blade passage frequencies are obtained by summing five spectral amplitudes, that is, the blade passage frequency harmonic plus two on either side, to account for the fact that the tonal peak may be spread over multiple frequency bins. The subsequent data processing steps are individually applied to the separated broadband and tonal components. In addition, adjustments were applied to account for differences between the test article and the 
aircraft engine model. These include differences in count, spacing and design of the fan blade and exit guide vanes, and the exit geometry. Fan RPM and pressure ratio (FPR) were additionally modified to represent flight conditions.

\section{B. Tunnel-to-Flight Condition Processing}

The data were converted from wind tunnel to International Standard Atmosphere (ISA) conditions by

$$
\begin{aligned}
S P L_{\text {ISA }} & =S P L_{\text {Tunnel }}+10 \log _{10}\left[1-M_{\text {Tunnel }} \cos \theta_{E}\right]^{\text {SUE }}-10 \log _{10}\left[\left(\rho_{\text {Tumnel }} / \rho_{\text {ISA }}\right)^{2}\left(c_{\text {Tunnel }} / c_{\text {ISA }}\right)^{4}\right] \\
& =S P L_{\text {Tunnel }}+10 \log _{10}\left[1-M_{\text {Tunnel }} \cos \theta_{E}\right]^{\text {SUE }}-10 \log _{10}\left(P_{\text {Tunnel }} / P_{\text {ISA }}\right)^{2}
\end{aligned}
$$

in which the second term on the right hand side removes the effect of convective amplification included in the measured tunnel data, and the third term is a source strength amplitude adjustment to correct the tunnel conditions to ISA conditions. Here, $M_{\text {Tunnel }}=0.2$, the source motion exponent $(S M E)$ is taken as 2 for a dipole source, and the emission angle $\theta_{E}$ is computed from the geometric angle $\theta_{G}$ by

$$
\theta_{E}=\theta_{G}-\arcsin \left[M_{\text {Tunnel }} \sin \theta_{G}\right] .
$$

There is no frequency shift since the relative velocity between the source and the microphone is zero. The data were next converted to flight conditions by

$$
S P L_{\text {Flight }}=S P L_{I S A}-10 \log _{10}\left[1-M_{\text {Flight }} \cos \theta_{E}\right]^{S M E}
$$

in which the second term on the right hand side adds the effect of convective amplification for the particular $M_{\text {Flight }}$. When the data is used as input to ANOPP, the Doppler frequency shift

$$
f_{\text {Flight }}=f_{\text {Tumnel }} /\left[1-M_{\text {Flight }} \cos \theta_{E}\right]
$$

must be applied. However, this factor is not applied to the tonal data used as input to auralization because the propagation process simulates the Doppler shift (see Section IV.B).

Conversion from model-scale to full-scale affects both amplitudes and frequencies. Here, the geometric scale factor $S F\left(D_{\text {Model-Scale }} / D_{\text {Full-Scale }}\right)$ was used giving the amplitudes as

and the frequencies as

$$
S P L_{\text {Flight } @ \text { Full-Scale }}=S P L_{\text {Flight }}+20 \log _{10}(1 / S F)
$$

$$
f_{\text {Fight@ Full-Scale }}=f_{\text {Filght }} \times S F .
$$

The noise impact of the stator soft vane was applied to the narrowband source spectra. The narrowband spectra were then converted to $1 / 3$-octave band spectra, ranging from $50 \mathrm{~Hz}$ to $10 \mathrm{kHz},{ }^{24}$ for use in the ANOPP Acoustic Data (ANOPP-ACD) module. The noise impact of the duct acoustic liner and acoustic scattering from PAA interactions were subsequently applied to the 1/3-octave band spectra. The auralization uses the broadband component after treatment and suppression are applied, but uses the full-scale un-Dopplerized tonal data and applies treatment and suppression external to ANOPP2.

\section{Auralization Methodology}

Like the system noise prediction, the auralization methodology takes a source-path-receiver approach. Pressure time histories of the source are synthesized from source noise definitions. Propagation of the pressure time histories to a ground observer is performed in the time domain based on the path, and simulates spherical spreading loss, atmospheric absorption, Doppler shift via time-varying propagation time delay, and ground plane reflection. The received pressure time history for the flyover may be post-processed to obtain integrated certification and sound quality metrics.

\section{A. Source Noise Synthesis}

The pressure time history at the source position is synthesized at the emission time based upon the instantaneous source spectrum. The instantaneous source spectrum is, in general, a function of both the emission angle and the operational state of the aircraft. The emission angle is determined by the straight line path between the source and receiver and is typically calculated at an update rate on the order of $100 \mathrm{~Hz}$. The operational state is specified at waypoints in the trajectory at a much lower rate, on the order of seconds. Note that because convective 
amplification is incorporated in the source noise hemispheres, its effect is automatically realized in the synthesized signal. This approach has been implemented in the NASA Auralization Framework (NAF) ${ }^{25}$ and is depicted in Figure 2.

The NAF synthesizes pressure time histories in a manner dependent on the source spectrum specified, as indicated in Table 2. A pressure time history that continually evolves with changes in source directivity is critical in order to avoid sudden changes in character resulting from a discretized source spectrum. For spectra expressed in power spectral density (PSD) form, the NAF synthesizes the broadband noise using an overlap-add technique ${ }^{26,27}$ If the source specification is Doppler-shifted, it is de-Dopplerized prior to synthesis so that the Doppler shift is not applied twice, i.e., once in the source noise definition and again during propagation (see Section IV.B). For spectra expressed as tonal amplitudes, the NAF synthesizes the noise in the time domain in a manner which permits changes in amplitude and frequency as a function of time. ${ }^{28}$ The output of the synthesis process is analogous to the signal that a single microphone would record at some reference distance near the flying source, but in the far field. As the source moves, the emission angle changes in a continuous fashion and, by analogy, the microphone location smoothly traverses the hemisphere below the aircraft. In this manner, the source directivity is embedded in the synthesized signal and does not need to be explicitly represented in the propagation stage. This approach to synthesis makes simulation of arbitrary trajectories straightforward.

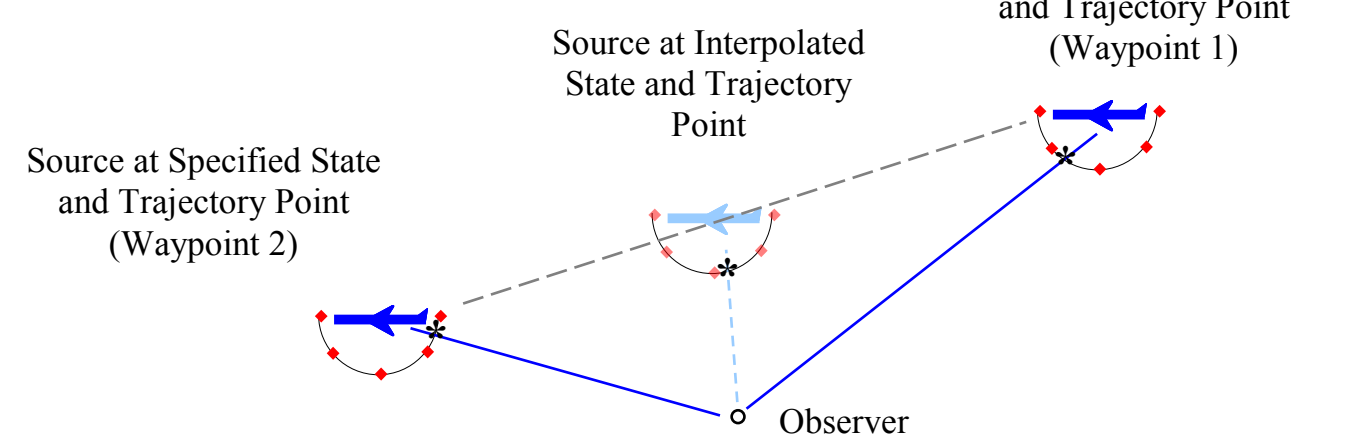

Figure 2: Synthesis is performed at the directivity angle (denoted by $\left.{ }^{*}\right)$ at the time of emission.

\section{B. Propagation}

Propagation of the source noise to a ground observer occurs in the time domain through application of a timedependent gain, time delay, and filter to the source noise. ${ }^{26,27}$ The propagation process accounts for spherical spreading loss, atmospheric absorption and time delay, as well as optionally including ground plane reflection. The time varying nature of these quantities is governed by the propagation path.

The straight-line path between the source and observer is computed at evenly spaced emission times corresponding to the synthesis hop size. Spherical spreading loss is dependent on the slant range, giving a timedependent negative gain. The time delay is a function of the speed of sound and slant range, and its time rate of change simulates Doppler shift. The only accurate and consistent approach currently available between the ANOPP2 analysis (using the ANOPP PRO module for propagation) and the auralization for a straight path is to specify a uniform atmosphere such that the speed of sound is constant. ${ }^{5}$

Atmospheric absorption is accumulated along the straight line path through the specified atmosphere at each $1 / 3$ octave band center frequency. The absorption curve is fit with a $2^{\mathrm{n}}$-point spline and converted to a minimum phase finite impulse response (FIR) filter via an inverse fast Fourier transform (FFT), as described by Rizzi and Sullivan. ${ }^{26}$ The filter is slant range dependent and, therefore, varies in time with the moving source.

Once the time-dependent gain, time delay, and filter are known, the synthesized signal is propagated by filtering the time-delayed signal in the time domain and applying the time-dependent spreading loss to the result. The propagation stage is performed as part of the NASA Community Noise Test Environment ${ }^{27}$ (CNoTE) simulator application. The output of the propagation stage is a pseudo-recording at the observer location.

Finally, ground plane reflection may be optionally applied according to either a hard surface (infinite) or finite impedance boundary. The interference caused by the addition of the propagated direct and reflected rays produces a comb filter effect, which alters the spectral content in a time-varying manner as the aircraft moves along its trajectory.

Pseudo-recordings of the propagated synthesized noise are post-processed using the ANOPP2 ${ }^{10}$ Acoustic Analysis API to generate aircraft certification metrics, in particular, tone-corrected perceived-noise level (PNLT) 
and effective perceived noise level (EPNL), for comparison with those obtained from the ANOPP2 system noise predictions. Sound quality metrics, e.g., loudness, sharpness, roughness, fluctuation strength and tone-to-noise ratio, are generated from the pseudo-recordings using the HEAD acoustics ArtemiS Suite ${ }^{29}$ software.

\section{Results}

Auralizations of each of the twenty-four aircraft conditions listed in Table 1 were performed using the approach described above. The aircraft trajectory, speed, operating conditions (e.g., throttle, flap, gear settings), etc., were as specified by Thomas et al. ${ }^{4}$ A uniform atmosphere at mean sea level ISA conditions $\left(15^{\circ} \mathrm{C}\right.$ temperature, $\left.1 \mathrm{~atm}\right)$ and $70 \%$ relative humidity was specified, and atmospheric absorption was calculated using the ANSI S1.26-1995 standard ${ }^{30}$ with the Zuckerwar update, ${ }^{11}$ as described by Rizzi and Sullivan. ${ }^{26}$ The ground was considered acoustically hard, and the receiver was either flush to the ground, resulting in a $6.02 \mathrm{~dB}$ increase across all frequencies, or at the certification microphone height of $3.94 \mathrm{ft}$. The approach observer position was located on the flight path at a point where the aircraft passed $394 \mathrm{ft}$. overhead on a 3-degree glide slope. The sideline observer position was located at a lateral distance of $1476 \mathrm{ft}$. and at a downrange distance where the aircraft reached an altitude of $1000 \mathrm{ft}^{4}$ Thus, the sideline observer location differed slightly for each aircraft.

The broadband synthesis used an FFT size of 8192 points, with a hop size of 512 points, or $11.6 \mathrm{~ms}$ at a synthesis sampling rate of $44.1 \mathrm{kHz}$. Tonal synthesis was performed at the same sampling rate. All relevant components were summed in the time domain at the source, and propagated to generate the total aircraft flyover noise at the receiver. The resulting pseudo-recordings were post-processed using the ANOPP2 ${ }^{10}$ Acoustic Analysis API with a block size of 32,768 and a segment length of $0.5 \mathrm{~s}$. Tone corrections located in bands below the $800 \mathrm{~Hz}$ $1 / 3$-octave band were omitted from the PNLT and EPNL calculations to minimize the influence of non-aircraft sources such as ground reflections. Finally, it was previously found that, for long propagation distances, the pseudorecording in the $10 \mathrm{kHz} 1 / 3$-octave band could effectively be numerically zero due to high absorption at high frequency. ${ }^{5}$ This resulted in anomalous tone penalties due to the manner in which PNLT is calculated for the highest $1 / 3$-octave band. For the purposes of the PNLT and EPNL calculations only, the $10 \mathrm{kHz} 1 / 3$-octave band level was extrapolated from the 6.3 and $8 \mathrm{kHz}$ levels. This eliminates any artificially high tone penalty.

Monaural pseudo-recordings coupled with animations of reference and $\mathrm{N}+2$ aircraft operating under the conditions listed in Table 1 are available for download. ${ }^{31}$ Relative levels between aircraft have been retained in their production.

\section{A. Certification Metrics}

It is useful to first compare metrics obtained from system noise predictions with those obtained from auralization results to establish parity between the two sets of results. To that end, consider PNLT traces of the LTA reference and HWB301-GTF-ITD aircraft on approach; see Figure 3 and Figure 4 for simulated ground and $3.94 \mathrm{ft}$. microphone locations, respectively. With respect to the ground microphone location (Figure 3), the excellent comparison between ANOPP2 and auralization-generated PNLT time histories demonstrates consistency between the two methods. Here, it is seen that the reference vehicle noise is substantially greater than the HWB301-GTFITD aircraft noise. The peak noise of the HWB301-GTF-ITD aircraft occurs later than the LTA reference aircraft due to its lower approach speed. The lower portion of the plot shows that the time near the overhead region $\left(90^{\circ}\right)$ for the HWB301-GTF-ITD lags that of the reference vehicle. Differences between the system noise prediction and auralization-generated EPNL of 0.4 and $0.23 \mathrm{EPNdB}$, for the LTA reference and HWB301-GTF-ITD aircraft, are typical of the quality of comparison achievable (see Table 3 ). The average difference across all 24 cases was 0.36 EPNdB. It was previously reported that differences in the way ground reflections are handled between the system noise prediction and auralization give rise to differences in the PNLT traces. ${ }^{5}$ In particular, the system noise prediction method performs propagation in the frequency domain while the auralization performs that operation in the time domain. This results in phase differences between the two methods when combining the direct and groundreflected noise, which in turn incurs different tone penalties at different times. This effect is clearly seen in Figure 4 and results in somewhat larger differences in EPNdB ( 0.53 and 0.47 for the LTA reference and HWB301-GTF-ITD aircraft, respectively) as indicated in Table 3 . The average difference across all 24 cases increased slightly from 0.36 to $0.39 \mathrm{EPNdB}$ for the elevated microphone location.

Summaries of the change in EPNL (generated from auralization) of the $\mathrm{N}+2$ aircraft relative to their respective reference aircraft are shown in Figure 5 and Figure 6 for the approach and sideline conditions, respectively, for the $3.94 \mathrm{ft}$. microphone location. Here it is seen that the introduction of ITD noise reduction technologies yield about 0.5-1 EPNdB additional reduction in EPNL relative to the reference vehicles. It is interesting to note that the T+W160-GTF in the SA class achieves comparable noise reduction on approach and sideline, whilst the LTA class 
aircraft achieve substantially more noise reduction on approach than on sideline. Also with respect to the LTA class, the aircraft configuration (T+W, HWB and MFN) has more to do with the amount of noise reduction on approach than does the engine type (DD vs GTF). This is readily seen by comparing T+W301-DD and T+W301GTF with HWB301-GTF and MDN301-GTF. Conversely, for the sideline condition, the engine type has more influence on the noise reduction than does the configuration. Compare T+W301-GTF, HWB301-GTF and MFN301-GTF with T+W301-DD. The last two observations are consistent with the work by Thomas et al. ${ }^{4}$ in which it was shown that the contribution of airframe noise sources is close to or above the engine sources on approach, and well below the engine sources at sideline for the T+W301-GTF and HWB301-GTF vehicles (see Figures 14-17 in the subject reference).

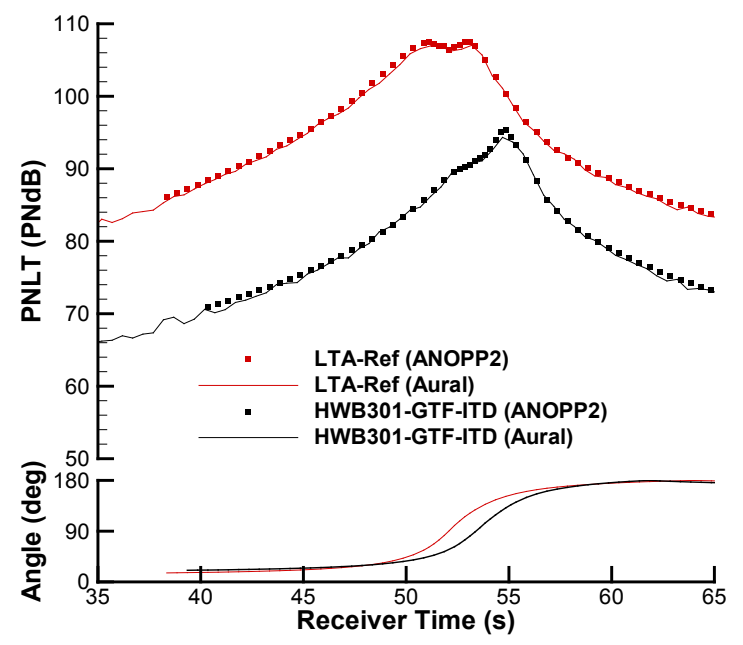

Figure 3: Comparison of PNLT for selected LTA class aircraft on approach at a simulated ground microphone.

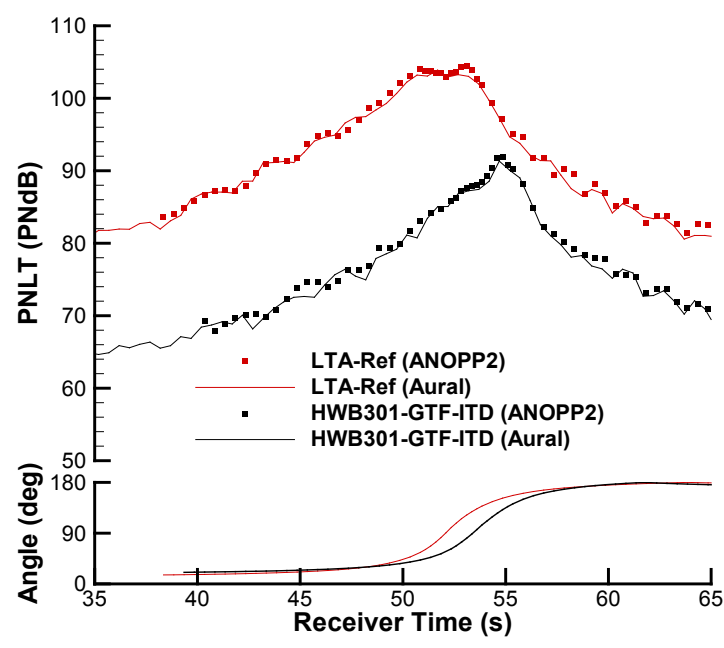

Figure 4: Comparison of PNLT for selected LTA class aircraft on approach at a simulated $3.94 \mathrm{ft}$. microphone.

Table 3: Comparison of EPNL (EPNdB) between ANOPP2 and auralization for two LTA aircraft on approach.

\begin{tabular}{|l|c|c|c|c|}
\hline \multicolumn{1}{|c|}{ Vehicle } & $\begin{array}{c}\text { ANOPP2 } \\
\text { (ground mic) }\end{array}$ & $\begin{array}{c}\text { Auralization } \\
\text { (ground mic) }\end{array}$ & $\begin{array}{c}\text { ANOPP2 } \\
(3.94 \mathrm{ft} . \mathrm{mic})\end{array}$ & $\begin{array}{c}\text { Auralization } \\
(3.94 \mathrm{ft} . \mathrm{mic})\end{array}$ \\
\hline \hline LTA-Ref & 104.35 & 103.95 & 101.09 & 100.56 \\
\hline HWB301-GTF-ITD & 89.15 & 88.92 & 85.91 & 85.44 \\
\hline
\end{tabular}

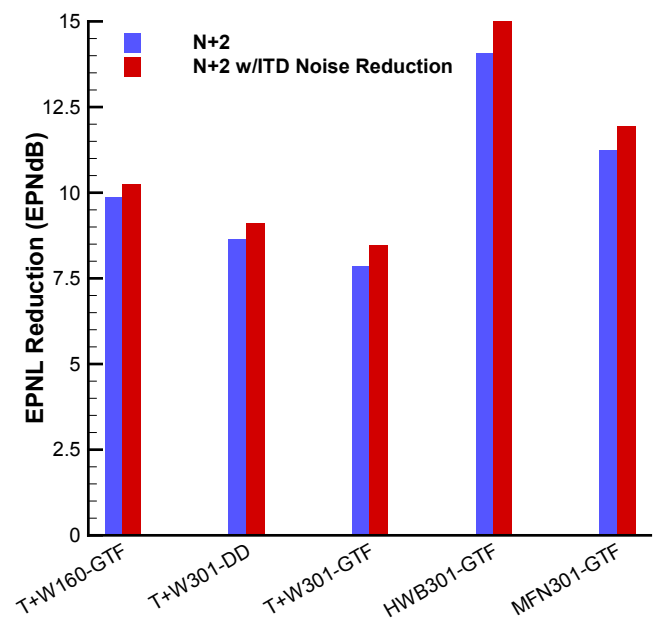

Figure 5: EPNL reduction between selected N+2 vehicles and their respective reference on approach.

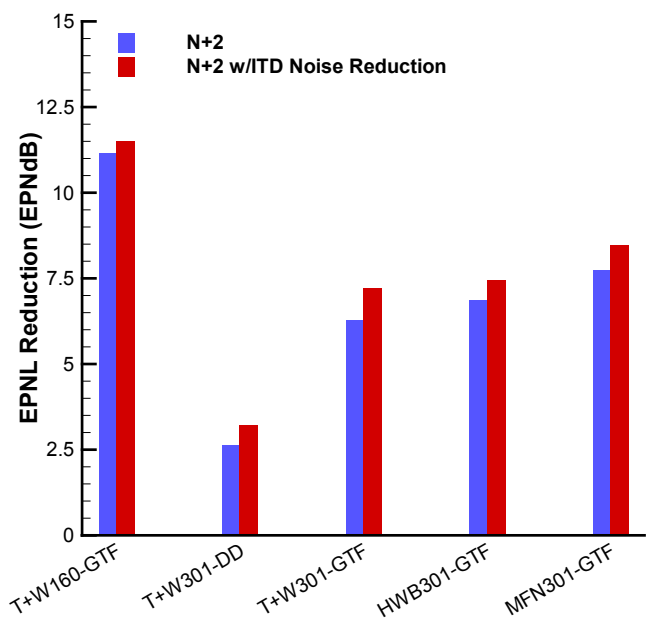

Figure 6: EPNL reduction between selected $\mathrm{N}+2$ vehicles and their respective reference on sideline. 


\section{B. Time-Frequency Response}

Spectrograms are useful for indicating the frequency response of the sound pressure level as a function of time. Their calculation on a narrowband basis is made possible through auralization. Shown in Figure 7 are the spectrograms for the LTA class aircraft on approach (a-e) and on sideline (f-j) at the $3.94 \mathrm{ft}$. observer position. Of the N+2 aircraft considered, only those with ITD noise reduction are shown, as those without ITD noise reduction appear very similar to their counterparts. For both the approach and sideline conditions, the interference between the direct and ground reflected rays produces a distinctive audible effect, which reveals itself in the spectrogram as notches in the frequency spectrum which change as a function of time. Setting our focus on the approach condition, a bird's-eye view of the spectrogram amplitudes indicates consistency with the EPNL reductions shown in Figure 5. The propulsion airframe aeroacoustic (PAA) effects are clearly visible, with the conventional $\mathrm{T}+\mathrm{W}$ configurations (a-c) exhibiting a double peak in the overhead region, while the unconventional configurations of the HWB301 (d) and MFN (e) show a singular peak. This is noted also in the PNLT traces of Figure 3 and Figure 4 and reflects the shielding of the forward radiated noise offered by the unconventional configurations. A close inspection of the spectrograms also reveals reduced tonal fan noise for the aircraft with GTF engines (c-e) relative to the already low fan noise associated with aircraft having DD engines (a-b). The different alignment of the peak levels in time between aircraft reflects their different approach speeds.

Next consider the sideline spectrograms in Figure $7(\mathrm{f}-\mathrm{j})$. As was the case for the approach, these are qualitatively consistent with the EPNL reductions shown in Figure 6. Shielding effects associated with the unconventional configurations of the HWB301 (i) and MFN (j) are most noticeable in the reduced forward radiated noise relative to the conventional $\mathrm{T}+\mathrm{W}$ configurations (f-h). Most striking is the significant contribution of the tonal fan noise for the aircraft with direct drive engines (f-g), relative to those with GTF engines (h-j). This accounts for the lower EPNL reduction for the T+W301-DD over the T+W301-GTF configurations (with and without ITD noise reduction) as seen in Figure 6. Here, the misalignment in peak levels in time is partially due to the different takeoff speeds and partially due to the different downrange observer positions.

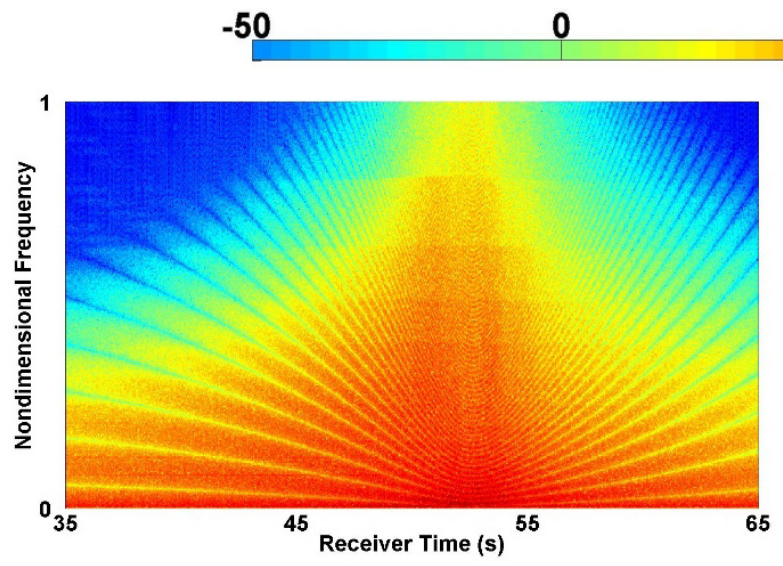

(a) LTA-Ref approach condition

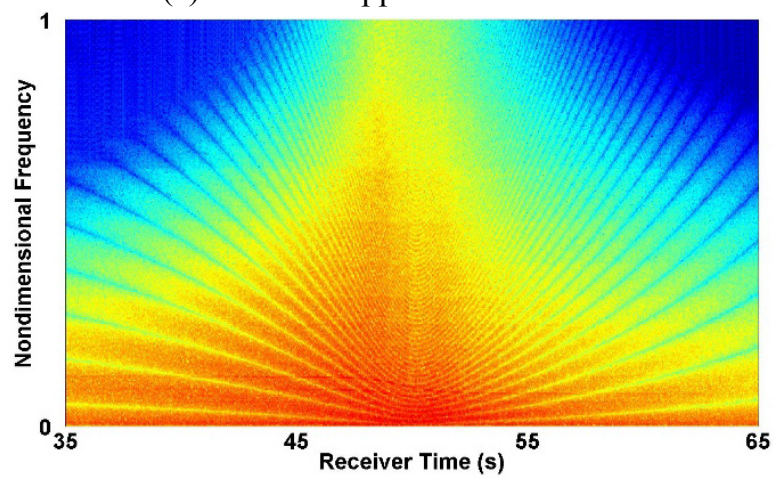

(b) T+W301-DD-ITD approach condition
$50 \quad 100 \mathrm{SPL}(\mathrm{dB})$

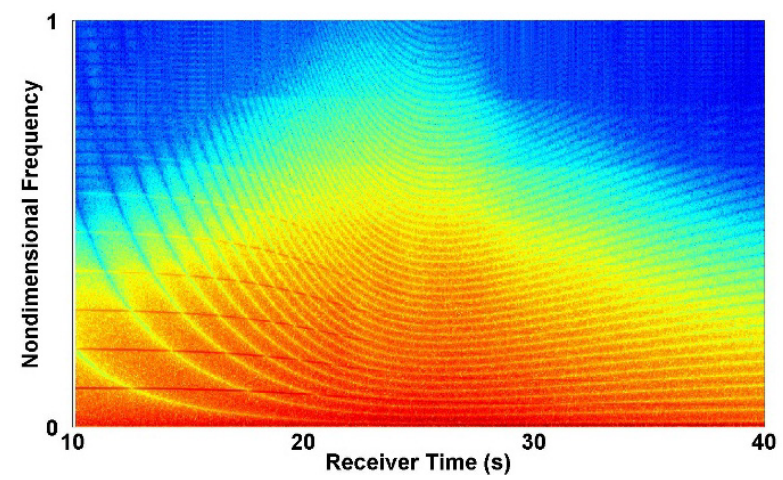

(f) LTA-Ref sideline condition

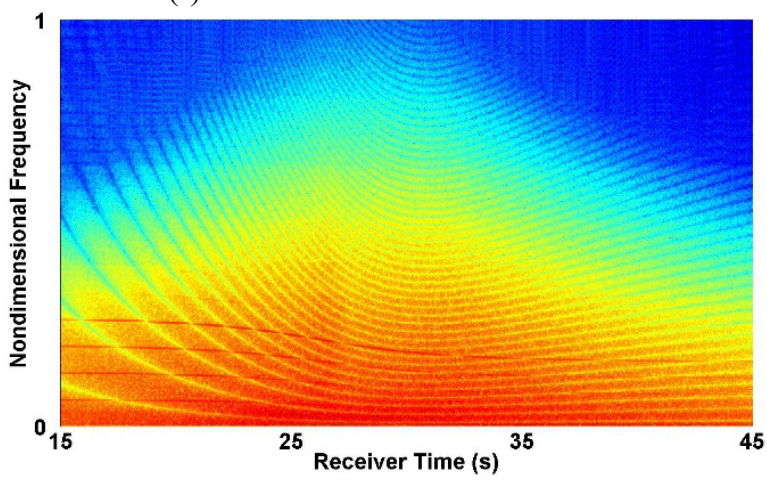

(g) T+W301-DD-ITD sideline condition

Figure 7: Spectrograms of auralized flyover noise for LTA class aircraft on approach (a-e) and sideline (f-j) conditions. A large dynamic SPL range was used to aid visualization. [concluded on next page] 


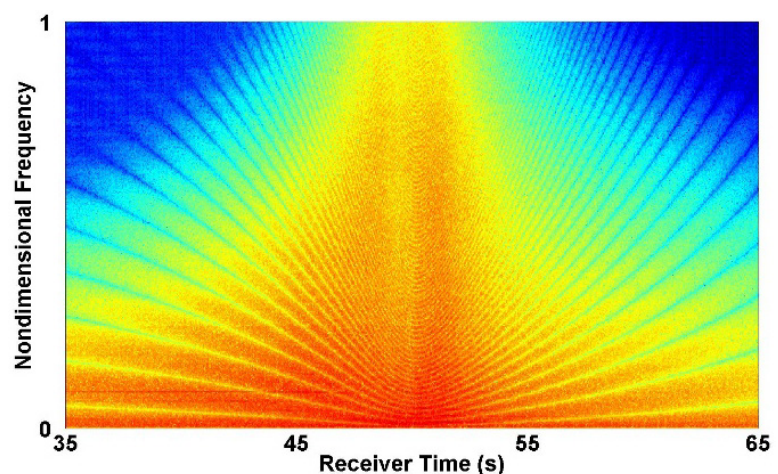

(c) T+W301-GTF-ITD approach condition

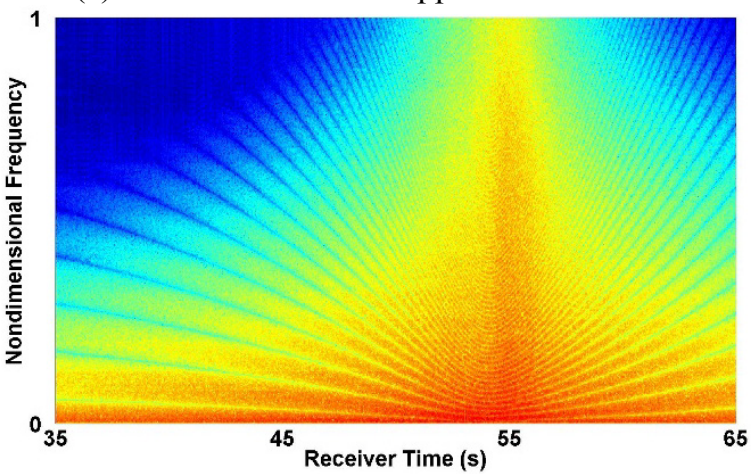

(d) HWB301-GTF-ITD approach condition

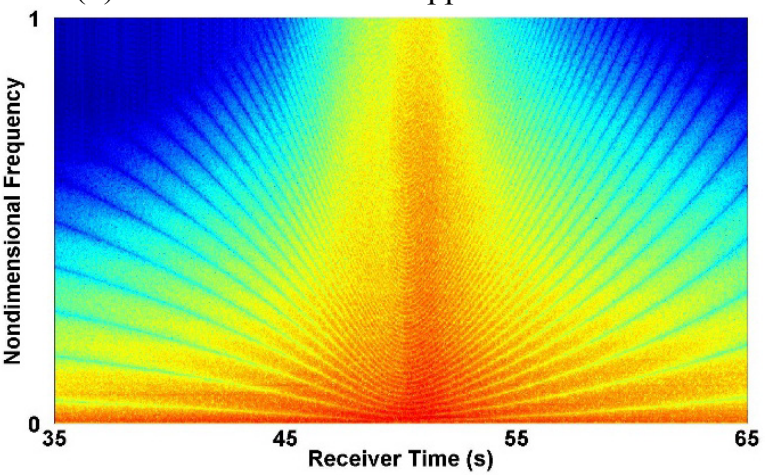

(e) MFN301-GTF-ITD approach condition

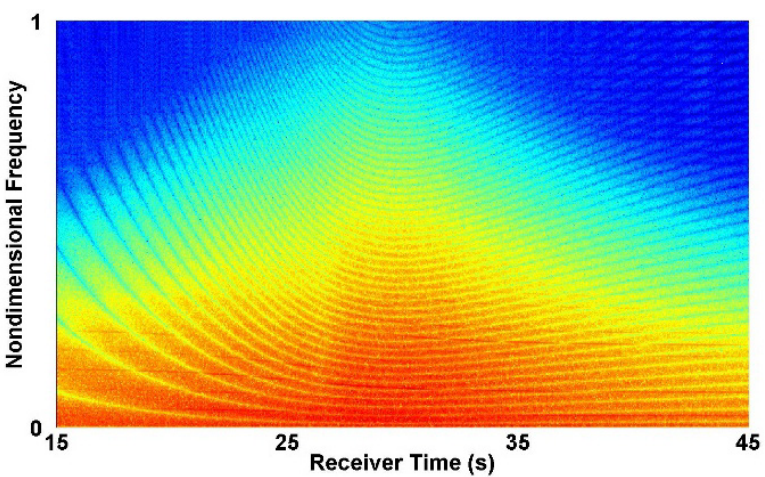

(h) T+W301-GTF-ITD sideline condition

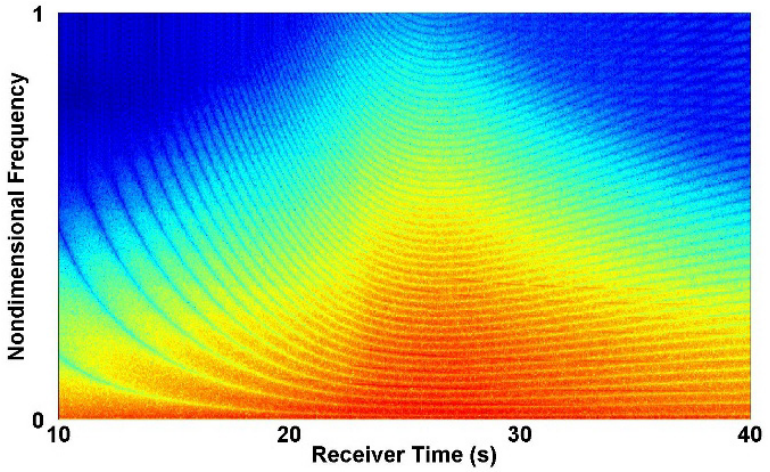

(i) HWB301-GTF-ITD sideline condition

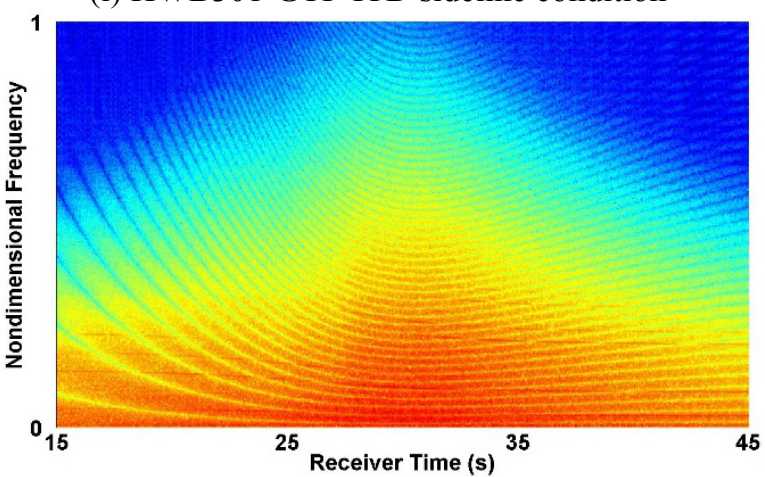

(j) MFN301-GTF-ITD sideline condition

Figure 7: Spectrograms of auralized flyover noise for LTA class aircraft on approach (a-e) and sideline (f-j) conditions. A large dynamic SPL range was used to aid visualization. [continued from previous page]

Spectrograms of the SA class aircraft at the $3.94 \mathrm{ft}$. observer position, shown in Figure 8, exhibit similar interference patterns as seen in Figure 7. Noteworthy is the presence of strong tones for the reference aircraft on approach (a) and on sideline (c). Tonal amplitudes are reduced to a lesser degree (compared to the reference) for the single-aisle T+W160-GTF-ITD aircraft on sideline than they are for the LTA class; compare Figure 8 (c) and (d) with Figure 7 (f) and (h). Additionally, the tones are more prominent on the approach condition for the SA class than for the LTA class. For the SA reference aircraft on sideline, the locally high amplitude band (extending from $10-20^{+} \mathrm{s}$ ) about the lowest blade passage frequency tone is attributable to the spectrum function in the Krejsa broadband fan source noise prediction within the ANOPP HDNFAN module. ${ }^{12}$ As this is a function of engine cycle, it is not present under all DD engine operating conditions. In this instance, its presence did not affect the tone penalty used in the PNLT calculation (not shown), and consequently it had little effect on the calculated EPNL value. 


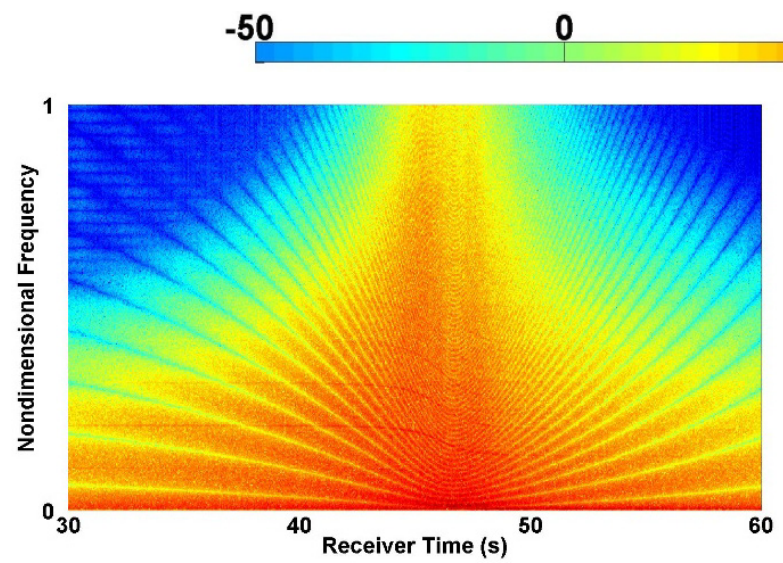

(a) SA-Ref approach condition

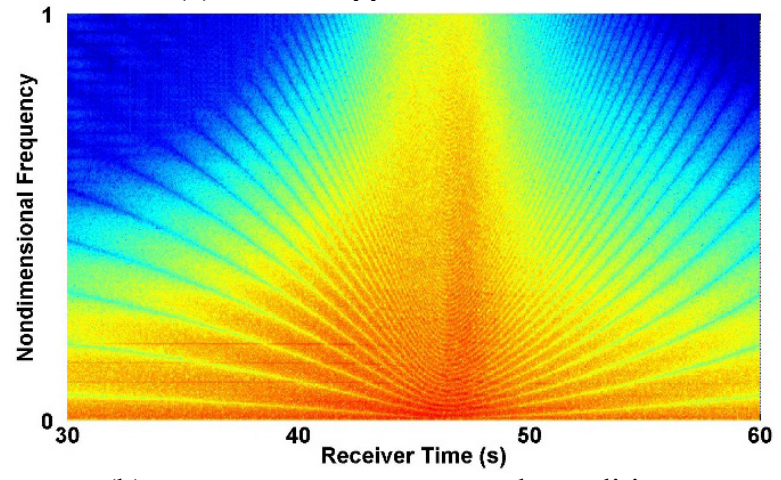

(b) T+W160-GTF-ITD approach condition
$50 \quad 100$ SPL (dB)

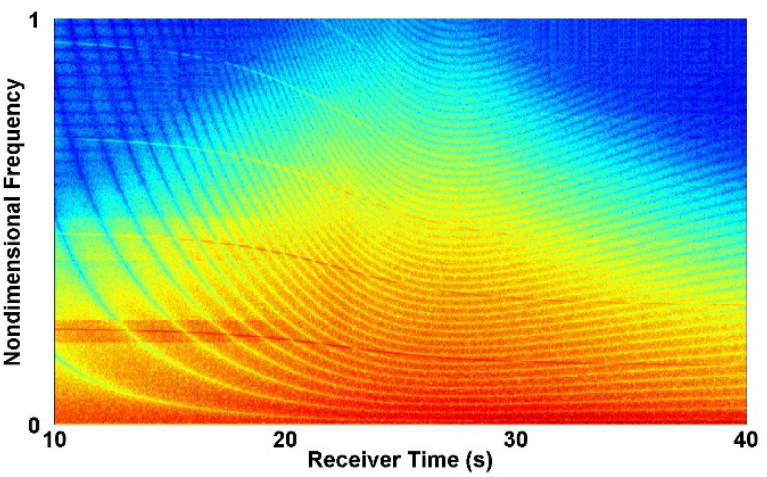

(c) SA-Ref sideline condition

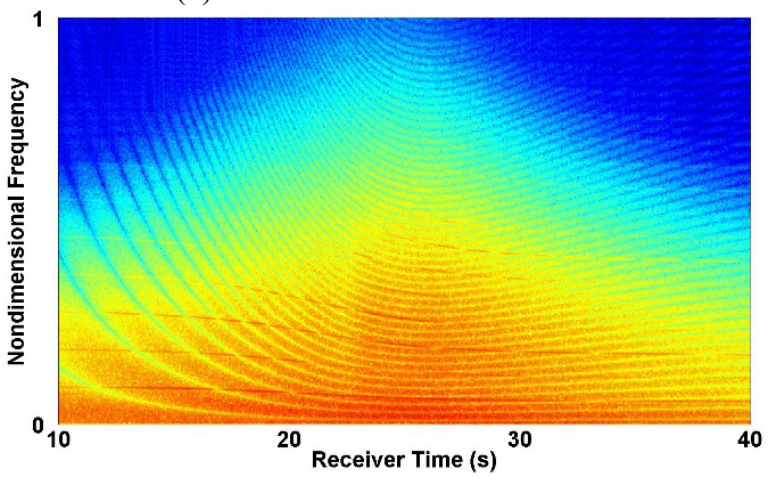

(d) T+W160-GTF-ITD sideline condition

Figure 8: Spectrogram of auralized flyover noise for SA class aircraft on approach (a-b) and sideline (c-d) conditions. A large dynamic SPL range was used to aid visualization.

\section{Sound Quality Metrics}

Psychoacoustic, or sound quality, metrics offer an additional means of describing level, spectral and temporal content. Four metrics are initially considered: the time-varying loudness $N(t)$ in sone, the time-varying sharpness $S(t)$ in acum, the time-varying roughness $R(t)$ in asper, and time-varying fluctuation strength $F(t)$ in vacil. Briefly, time-varying loudness reflects the human perception of the magnitude of the sound over time and is a function of the amplitude and frequency. Sharpness is an indicator of the spectral balance of a signal; the greater the amount of high frequency content, the greater the sharpness value. Roughness reflects the perception of rapid $(15-300 \mathrm{~Hz})$ amplitude modulation, with a maximum impression reached when loudness fluctuations are about $70 \mathrm{~Hz}$. Finally, fluctuation strength is similar to roughness, but reflects perception of slow fluctuations $(1-16 \mathrm{~Hz})$, with a maximum effect at about $4 \mathrm{~Hz}$.

In the following, DIN standard 45631/A1 ${ }^{32}$ was used to compute time-varying loudness. Although there is no single standard for calculating sharpness, the method employed used DIN standards 45631/A1 and $45692^{33}$ to compute time-varying sharpness. This method of computing sharpness gave nearly identical results to the von Bismarck method ${ }^{34}$ for the signals considered, and unlike the Aures method ${ }^{35}$ is not loudness-dependent. There are no standard methods for calculating roughness and fluctuation strength. The ArtemiS Suite offers two methods for calculating roughness: one based on the hearing model ${ }^{36}$ and one based on a modulation analysis. The latter was used, as it was of greater amplitude and tracked more closely with the overall character of the signal than did the method based on the hearing model. The method for calculating the fluctuation strength was, however, based on the hearing model, as this was the only method available within the ArtemiS Suite. Both the roughness and fluctuation strength methods are loudness-dependent.

Time-varying loudness, sharpness, roughness and fluctuation strength are shown in Figure 9 - Figure 12 for the LTA reference and HWB301-GTF-ITD aircraft on the sideline condition for the $3.94 \mathrm{ft}$. microphone position. Loudness and roughness traces exhibit peak behavior at times corresponding to the peak SPL in their spectrograms. Note that the roughness values shown are typical of the other pseudo-recordings. The peak sharpness for the LTA reference aircraft precedes the peak SPL in its spectrogram. Sharpness levels for the other pseudo-recordings were 
of comparable amplitude. The fluctuation strength, shown with its initial transient removed, is of low amplitude for these and the other pseudo-recordings. While the influence of the ground plane reflection has a significant and distinctive audible effect, the sound quality traces do not significantly differ from those corresponding to the ground plane microphone location (not shown). For the ground plane cases, sharpness was not significantly affected, while the loudness, roughness, and fluctuation strength increased slightly due to pressure doubling at the rigid ground plane.

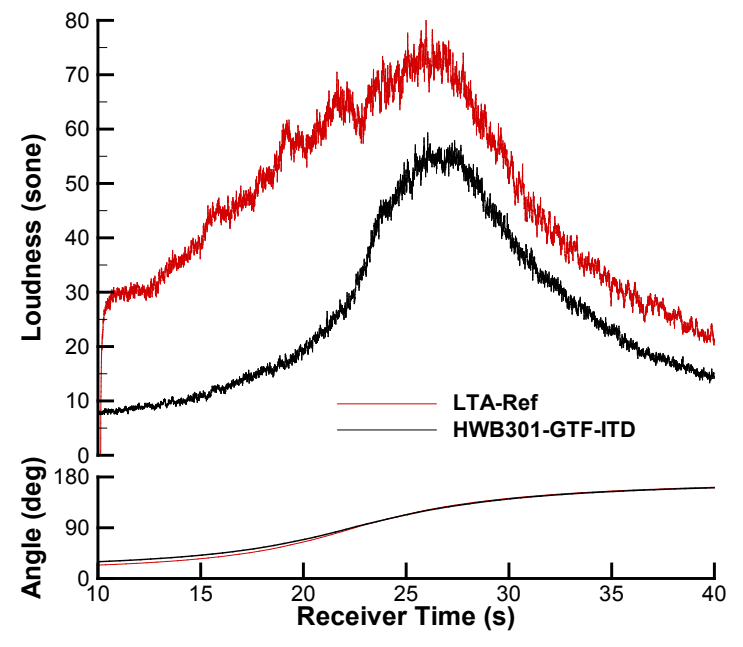

Figure 9: Comparison of time-varying loudness for selected LTA class aircraft on sideline at a simulated $3.94 \mathrm{ft}$. microphone.

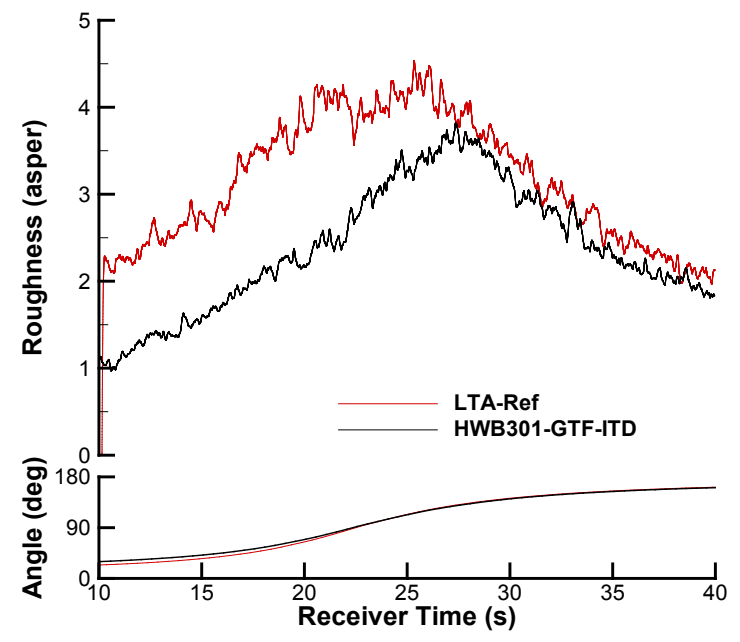

Figure 11: Comparison of time-varying roughness for selected LTA class aircraft on sideline at a simulated $3.94 \mathrm{ft}$. microphone.

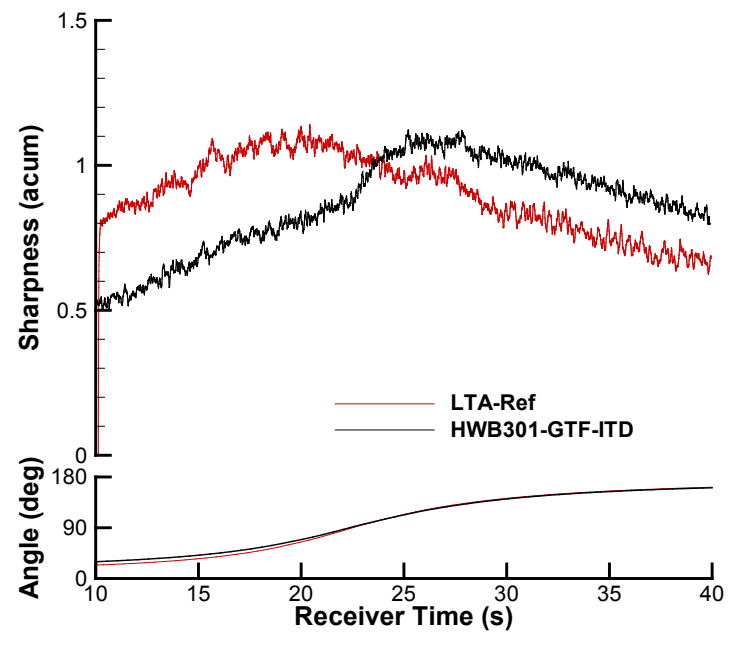

Figure 10: Comparison of time-varying sharpness for selected LTA class aircraft on sideline at a simulated $3.94 \mathrm{ft}$. microphone.

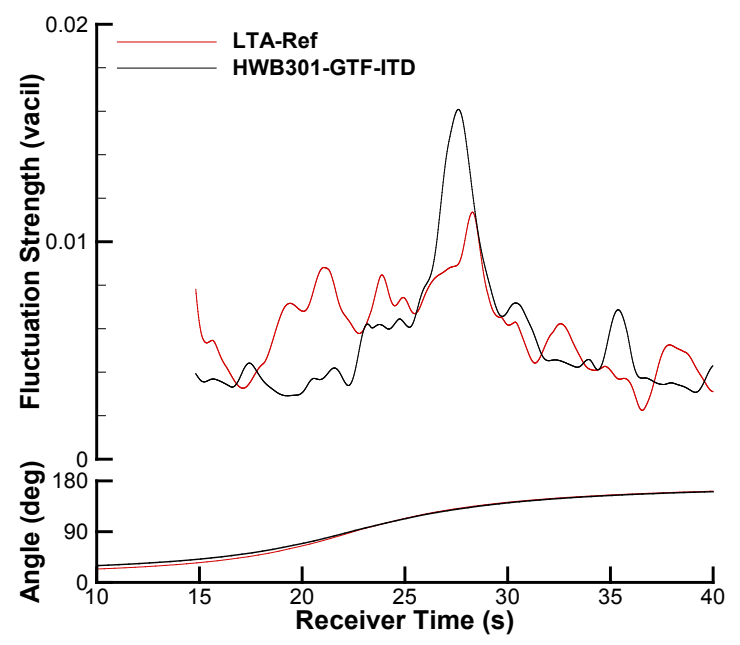

Figure 12: Comparison of time-varying fluctuation strength for selected LTA class aircraft on sideline at a simulated $3.94 \mathrm{ft}$. microphone.

\section{Psychoacoustic Annoyance Model}

One means of relating the sound quality metrics to the EPNL certification metric is through the Psychoacoustic Annoyance (PA) model, described by Zwicker and Fastl. ${ }^{37}$ The PA model offers a quantitative value of annoyance and is based on psychoacoustic tests using narrow- and broadband sounds having different spectral and temporal characteristics. A time-varying form is given by

$$
P A(t)=N(t)\left[1+\sqrt{w_{s}^{2}(t)+w_{F R}^{2}(t)}\right]
$$


in which

$$
\begin{gathered}
w_{s}(t)=\left\{\begin{array}{ccc}
0.25(S(t)-1.75) \log _{10}(N(t)+10) & \text { for } & S>1.75 \\
0 & \text { for } & S<1.75
\end{array}\right\}, \\
w_{F R}(t)=\frac{2.18}{N(t)^{0.4}}[0.4 F(t)+0.6 R(t)] .
\end{gathered}
$$

Note that although Eq. (9) is normalized by loudness, Zwicker and Fastl did not explicitly state that the reason for doing so was to account for the loudness dependency of roughness and fluctuation strength. Based on the 1.75 acum threshold indicated in Eq. (8) and the preceding metrics analysis, it can be concluded that sharpness does not play a role in the psychoacoustic annoyance results that follow. Similarly, the low values of fluctuation strength do not significantly contribute to the $w_{F R}$ term in Eq. (9). Hence, for the cases considered herein, the psychoacoustic annoyance, as expressed by Eq. (7), is loudness dominated and slightly influenced by roughness.

Calculation of psychoacoustic annoyance can be performed in one of two ways: on a time-varying basis or on an integrated basis. In the former, direct application of Eq. (7) results in a $P A$ time history. In the latter, metric percentiles may be used to provide a single $P A$ value. Zwicker and Fastl's original form of Eq. (7) used the $5^{\text {th }}$ percentile of loudness $\left(N_{5}\right)$, that is, the value of loudness which is exceeded $5 \%$ of the measurement time. However, the authors were not specific with respect to the percentiles for sharpness, roughness, and fluctuation strength. Consequently, two alternatives methods for calculating $P A \%$ are offered. In the first, the $5^{\text {th }}$ percentile is computed directly from the $P A$ time history to compute $P A_{5}$. In the second, $P A_{5}$ is computed using the $5^{\text {th }}$ percentiles of the individual metrics, that is, $N_{5}, R_{5}$ and $F_{5}$, in lieu of $N(t), R(t)$ and $F(t)$.

A benefit of using percentiles is that the event duration is implicitly taken into account. However, unlike the standardized EPNL calculation, ${ }^{2,3}$ which integrates PNLT between the -10 PNdB points on either side of the peak value, there is no standard for choosing the event duration for calculation of the $5^{\text {th }}$ percentiles. As the current use of the Psychoacoustic Annoyance model is intended to evaluate relative annoyance, the duration is somewhat arbitrary as long as it is consistent between sounds. In this work, a duration ranging from $15 \mathrm{~s}$ on either side of peak $P A(t)$ was chosen, for a total record length of $30 \mathrm{~s}$. Shown in Figure 13 is $P A(t)$ for the LTA reference and HWB301GTF-ITD aircraft on approach over their respective durations. The $P A_{5}$ values calculated directly from the $P A$ time histories are 201.9 and 78.0 for the LTA reference and HWB301-GTF-ITD aircraft, respectively. In comparison, the values computed using $N_{5}, R_{5}$ and $F_{5}$ are 202.2 and 78.2, respectively, demonstrating that both methods yield comparable values for the cases considered.

The percentile representation of $P A$, like EPNL, thus incorporates duration, level and spectral content. Therefore, it is of interest to determine if a relationship exists between EPNL and $P A_{5}$. Since EPNL is on a logarithmic scale and $P A$ is essentially linear in sone, a linear regression was performed between EPNL and $\log _{10}\left(P A_{5}\right)$. Figure 14 shows the least squares regression line when all 24 IDs (see Table 1) are included in the regression. Given that the flyover sounds are complex in character, the fact that $P A_{5}$ accounts for $80 \%$ of the variance seen in EPNL in remarkable.

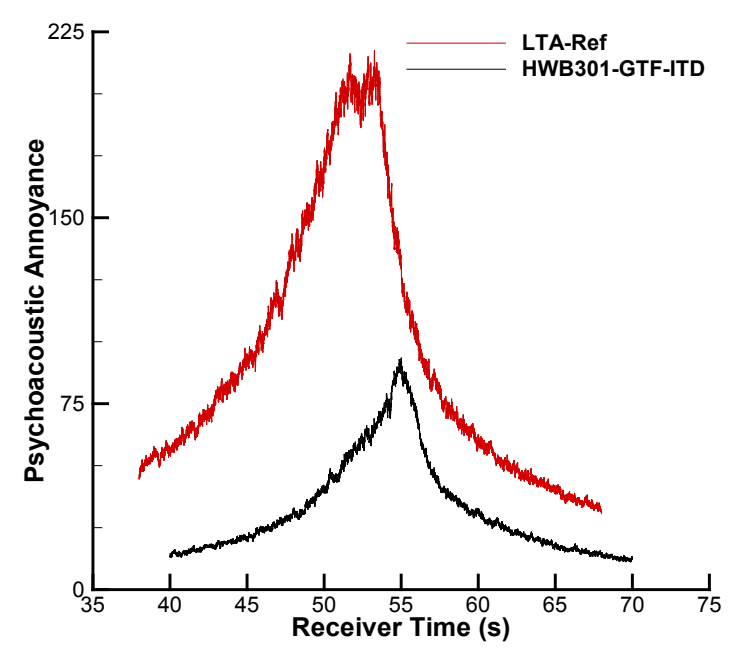

Figure 13: Comparison of time-varying PA on approach at a simulated $3.94 \mathrm{ft}$. microphone location.

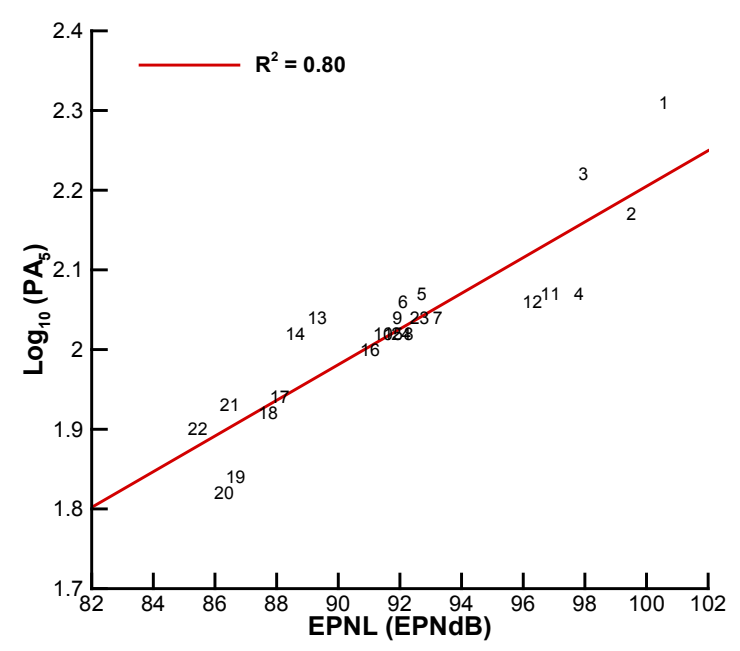

Figure 14: Linear regression between EPNL and $P A_{5}$ using all 24 cases at the $3.94 \mathrm{ft}$. microphone location. 
The above results notwithstanding, the $P A$ metric in Eq. (7) does not specifically account for tonal content, whereas EPNL does through the tone penalty applied to the perceived noise level (PNL) to obtain PNLT. Further, it was seen that some of the spectrograms exhibited strong tonal content. This suggests that the inclusion of sounds with strong tonal content should increase the mean square error between the regression line and the data, or conversely, the rejection of sounds with strong tonal content should decrease the error.

A convenient means of assessing the tonal contribution is the tone-to-noise ratio (TNR). An example TNR, computed using the ArtemiS Suite, is shown in Figure 15 for the LTA reference aircraft on the sideline condition. According to the ECMA-74 $4^{38}$ standard, tones are considered prominent if their tone-to-noise TNR ratio is $>8 \mathrm{~dB}$. Below $1 \mathrm{kHz}$, the threshold is increased by $2.5 \mathrm{~dB} /$ octave. The $1^{\text {st }}$ and $2^{\text {nd }}$ blade passage frequencies shown in Figure 15 clearly exceed this threshold. When the TNR analysis was applied to all auralizations, those exceeding the threshold were found to include IDs 2 (LTA-Ref), 4 (SA-Ref), $11 \& 12$ (T+W301-DD), and $19 \& 20$ (T+W160GTF). Not surprisingly, all are aircraft operating at the high-power sideline condition. Revisiting the linear regression between EPNL and $\log _{10}\left(P A_{5}\right)$ excluding these IDs, the coefficient of determination $\mathrm{R}^{2}$ increased from 0.8 to 0.9 , as seen in Figure 16. Finally, note that had a different duration been chosen for the $P A$ percentile calculation, the major effect would be a change in the $\log _{10}\left(P A_{5}\right)$ intercept, and not the slope of the least squares regression line or the $\mathrm{R}^{2}$ value.

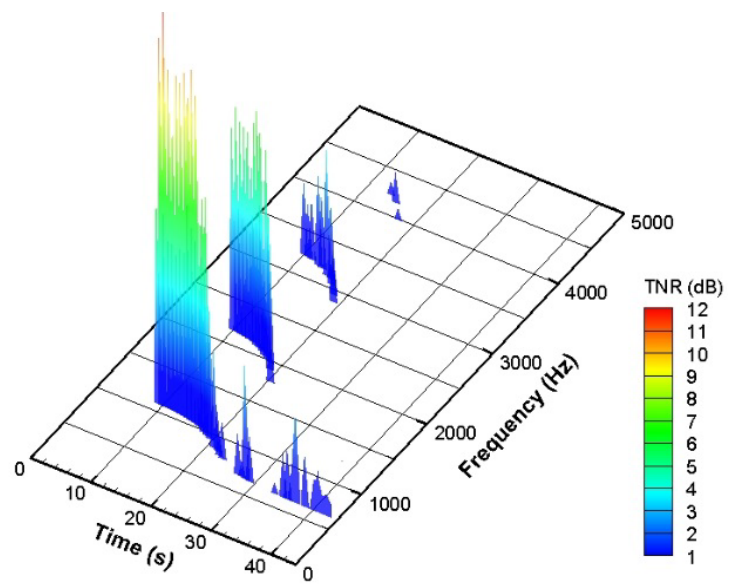

Figure 15: Tone-to-noise ratio for the LTA reference aircraft (ID 2) on the sideline operating condition.

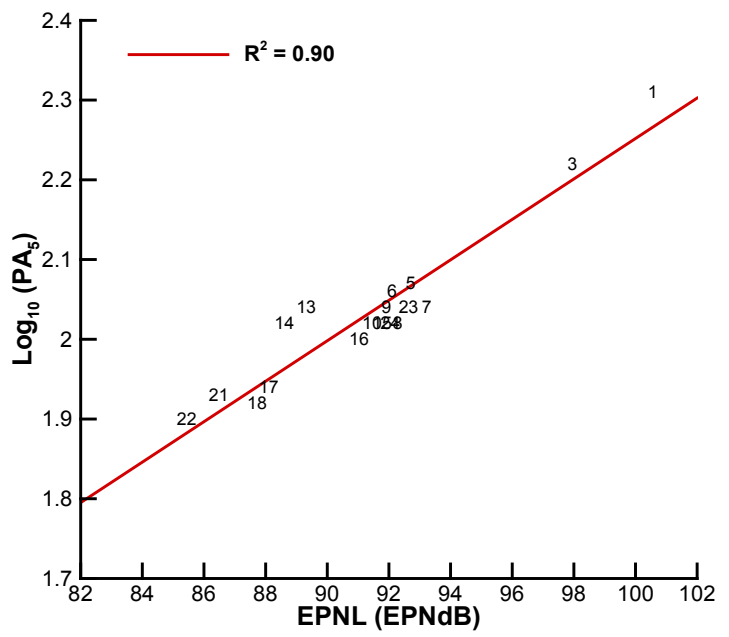

Figure 16: Linear regression between EPNL and $P A_{5}$ excluding cases with high tone-to-noise ratios.

The above analysis demonstrates the importance for including tonal content in $P A$ when the TNR indicates tones are prominent. To that end, More ${ }^{39}$ developed a modified Psychoacoustic Annoyance $\left(P A_{m o d}\right)$ model for aircraft noise based upon the sound quality metrics used in Zwicker and Fastl's $P A$ model, but also included Aures' tonality. ${ }^{35}$ More employed a nonlinear least squares fit to estimate model coefficients using psychoacoustic test data from simulated aircraft sounds. Application of the $P A_{\bmod }$ model to the simulated $\mathrm{N}+2$ aircraft flyover noise is left for future consideration.

\section{Conclusions}

Auralizations of several NASA $\mathrm{N}+2$ aircraft configurations have been made possible through utilization of installed source noise definitions obtained from the final ERA system noise assessments. Noise certification metrics computed from auralization pseudo-recordings have been shown to be consistent with those obtained from the system noise assessments. These results again demonstrate that auralization is complementary to the system noise predictions and is an effective means of communicating the societal benefit of low-noise concepts to stakeholders.

For the auralizations considered, an evaluation of the sound quality metrics for loudness, sharpness, roughness, and fluctuation strength indicated that sharpness and fluctuation strength did not play a significant role according to a psychoacoustic annoyance model. An integrated metric for psychoacoustic annoyance, $P A_{5}$, which incorporates duration, level and spectral content, was shown to account for $90 \%$ of the variance seen in EPNL for signals having low tone-to-noise ratios. However, some single-aisle and large twin-aisle aircraft operating on the sideline condition 
were found to have tone-to-noise ratios that are considered prominent. When these cases were included in a linear regression analysis, $P A_{5}$ was shown to account for less of the variance seen in EPNL because the $P A$ metric does not explicitly introduce a tone penalty akin to what is employed in PNLT.

Finally, with the auralizations generated herein, the question posed in the Introduction can be addressed, i.e., How well do aircraft certification metrics, based on psychoacoustic studies conducted in the 1960s and '70s using measured noise from tube and wing designs with low bypass turbofan engines, reflect the human annoyance of these advanced vehicle concepts? This is the subject of a companion paper, ${ }^{9}$ which explores EPNL as a predictor of annoyance to advanced civil transport aircraft noise.

\section{Acknowledgments}

This work was performed with support from the Environmentally Responsible Aviation project of the NASA Integrated Aviation Systems Program and the Transformational Tools and Technologies project of the NASA Transformative Aeronautics Concepts Program. The authors wish to acknowledge the support of Analytical Mechanics Associates, Inc. (AMA) Studios in creation of the animations.

\section{References}

${ }^{1}$ Nickol, C.L. and Haller, W.J., "Assessment of the performance potential of advanced subsonic transport concepts for NASA's Environmentally Responsible Aviation Project," 54th AIAA Aerospace Sciences Meeting, AIAA 2016-1030, San Diego, CA, 2016.

${ }^{2}$ Anon., "Annex 16 to the Convention on International Civil Aviation, Environmental Protection, Volume I, Aircraft Noise (7th Edition)," International Civil Aviation Organization, Montreal, Canada, July, 2014.

${ }^{3}$ Anon., "14 CFR Parts 36 and 91, Stage 4 Aircraft Noise Standards," US Department of Transportation, Federal Aviation Administration, Federal Register, Washington, DC, July 5, 2005.

${ }^{4}$ Thomas, R.H., Burley, C.L., and Nickol, C.L., "Assessment of the noise reduction potential of advanced subsonic transport concepts for NASA's Environmentally Responsible Aviation Project," 54th AIAA Aerospace Sciences Meeting, AIAA 2016-0863, San Diego, CA, 2016.

${ }^{5}$ Rizzi, S.A., Aumann, A.R., Lopes, L.V., and Burley, C.L., "Auralization of hybrid wing-body aircraft flyover noise from system noise predictions," AIAA Journal of Aircraft, Vol. 51, No. 6, 2014, pp. 1914-1926.

${ }^{6}$ Christian, A., Boyd Jr., D.D., Zawodny, N.S., and Rizzi, S.A., "Auralization of tonal rotor noise components of a quadcopter flyover," InterNoise 2015, San Francisco, CA, 2015.

${ }^{7}$ Rizzi, S.A., Stephens, D.B., Berton, J.J., Van Zante, D.E., Wojno, J.P., and Goerig, T.W., "Auralization of flyover noise from open rotor engines using model scale test data," AIAA Journal of Aircraft, Vol. 53, No. 1, 2016, pp. 117-128.

${ }^{8}$ Rizzi, S.A. and Christian, A., "A method for simulation of rotorcraft fly-in noise for human response studies," InterNoise 2015, San Francisco, CA, 2015.

${ }^{9}$ Rizzi, S.A. and Christian, A., "A psychoacoustic evaluation of noise signatures from advance civil transport aircraft," To be presented at the 22nd AIAA/CEAS Aeroacoustics Conference, Lyon, France, 2016.

${ }^{10}$ Lopes, L.V. and Burley, C.L., "Design of the next generation aircraft noise prediction program: ANOPP2," 17th AIAA/CEAS Aeroacoustics Conference, AIAA 2011-2854, Portland, Oregon, 2011.

${ }^{11}$ Zorumski, W.E., "Aircraft noise prediction program theoretical manual," NASA TM-83199, 1982.

${ }^{12}$ Krejsa, E.A. and Stone, J.R., "Enhanced fan noise modeling for turbofan engines," Diversitech, Inc., Informal Report to NASA GRC Contract ID NNC05VD49P, December 31, 2005.

${ }^{13}$ Emmerling, J.J., Kazin, S.B., and Matta, R.K., "Core engine noise control program. Volume III, Supplement 1 - Prediction methods," FAA-RD-74-125, III-I (Available from DTIC as AD A030 376), March 1976.

${ }^{14}$ Stone, J.R., Krejsa, E.A., and Clark, B.K., "Jet noise modeling for suppressed and unsuppressed aircraft in simulated flight," NASA TM-2009-215524, March 2009.

${ }^{15}$ Guo, Y., "An improved landing gear noise prediction scheme," The Boeing Company, NASA Contract NAS1-NNL04AA11B (Task NNL06AB63T), November 2006.

${ }^{16}$ Guo, Y., "Empirical prediction of aircraft flap side edge noise," The Boeing Company, NASA Contract NAS1-00086 (Task NNL04-AD34T), August 2006.

${ }^{17}$ Sen, R., Hardy, B., Yamamoto, K., Guo, Y., and Miller, G., " Airframe noise sub-component definition and model," NASA CR2004-213255, September 2004.

${ }^{18}$ Fink, M., "Airframe noise prediction method " U.S. Department of Transportation, Federal Aviation Administration, FAA-RD 77-29, 1977.

${ }^{19}$ Fink, M., "Noise component method for airframe noise," AIAA Journal of Aircraft, Vol. 16, No. 10, 1979, pp. 659-665.

${ }^{20}$ Thomas, R.H., Burley, C.L., Lopes, L.V., Bahr, C.J., Gern, F.H., and Van Zante, D.E., "System noise assessment and the potential for a low noise Hybrid Wing Body aircraft with open rotor propulsion," 52nd Aerospace Sciences Meeting, AIAA-2014-0258, National Harbor, MD, 2014. 
${ }^{21}$ Burley, C.L., Brooks, T.F., Hutcheson, F.V., Doty, M.J., Lopes, L.V., Nickol, C.L., Vicroy, D.D., and Pope, D.S., "Noise scaling and community noise metrics for the Hybrid Wing Body aircraft," 20th AIAA/CEAS Aeroacoustics Conference, AIAA-2014-2626, Atlanta, GA, 2014.

${ }^{22}$ Guynn, M.D., Berton, J.J., Haller, W.J., Hendricks, E.S., and Tong, M.T., "Performance and environmental assessment of an advanced aircraft with open rotor propulsion," NASA TM-2012-217772, October 2012.

${ }^{23}$ Parry, A.B., Kingan, M., and Tester, B.J., "Relative importance of open rotor tone and broadband noise sources," 17th AIAA/CEAS Aeroacoustics Conference, AIAA-2011-2763, Portland, OR, 2011.

24"Octave, half-octave, third octave band filters intended for the analysis of sounds and vibrations," International Electrotechnical Commission (IEC) Publication 225, 1966.

${ }^{25}$ Aumann, A.R., Tuttle, B.C., Chapin, W.L., and Rizzi, S.A., "The NASA Auralization Framework and Plugin Architecture," InterNoise 2015, San Francisco, CA, 2015.

${ }^{26}$ Rizzi, S.A. and Sullivan, B.M., "Synthesis of virtual environments for aircraft community noise impact studies," 11th AIAA/CEAS Aeroacoustics Conference, AIAA-2005-2983, Monterey, CA, 2005.

${ }^{27}$ Rizzi, S.A., Sullivan, B.M., and Aumann, A.R., "Recent developments in aircraft flyover noise simulation at NASA Langley Research Center," NATO Research and Technology Agency AVT-158 "Environmental Noise Issues Associated with Gas Turbine Powered Military Vehicles" Specialists' Meeting, Paper 17, Montreal, Canada, 2008, NATO RTA Applied Vehicle Technology Panel, pp. 14.

${ }^{28}$ Allen, M.P., Rizzi, S.A., Burdisso, R., and Okcu, S., "Analysis and synthesis of tonal aircraft noise sources," 18th AIAA/CEAS Aeroacoustics Conference, AIAA-2012-2078, Colorado Springs, CO, 2012.

29"ArtemiS Suite," 12.2, HEAD acoustics GmbH, NVH Division, 2016.

30"American National Standard Method for the calculation of the absorption of sound by the atmosphere," American Institute of Physics, ANSI S1.26-1995 (ASA 113-1995), 1995.

31 "Aircraft flyover simulation," http://stabserv.larc.nasa.gov/flyover/, NASA, 2016.

32"Calculation of loudness level and loudness from the sound spectrum - Zwicker method - Amendment 1: Calculation of the loudness of time variant sound," Deutsches Institut für Normung (DIN) 45631/A1, 2009.

33 "Measurement technique for the simulation of the auditory sensation of sharpness," Deutsches Institut für Normung (DIN) 45692, 2009.

${ }^{34}$ von Bismarck, G., "Sharpness as an attribute of the timbre of steady sounds," Acta Acustica united with Acustica, Vol. 30, No. 3, 1974, pp. 159-172.

${ }^{35}$ Aures, W., "Berechnungsverfahren für den sensorischen Wohlklang beliebiger Schallsignale (Procedure for calculating the sensory euphony of arbitrary sound signals)," Acta Acustica united with Acustica, Vol. 59, No. 2, 1985, pp. 130-141.

${ }^{36}$ Sottek, R., "Modelle zur Signalverabeitung im menschlichen Gehör (Models for signal processing in the human ear)," Electrical Engineering and Information Technology, RWTH Aachen, Aachen, Germany, 1993.

${ }^{37}$ Zwicker, E. and Fastl, H. Second ed, Psychoacoustics, Facts and Models, ed. M.R. Schroeder. Springer-Verlag, Berlin, 1999.

38"Measurement of airborne noise emitted by information technology and telecommunications equipment," ECMA International, ECMA-74 10th Edition, 2008.

${ }^{39}$ More, S.R., "Aircraft noise characteristics and metrics," Ph.D. dissertation, Purdue University, West Lafayette, IN, 2010. 